\title{
Screening and Identification of Extended Spectrum $\beta$-lactamase (ESBL) Pathogens in Urine Sample of UTI Patient's
}

Jasmine Subashini and Krishnan Kannabiran*

School of Biosciences and Technology, VIT University, Vellore-632014, Tamil Nadu, India

\begin{abstract}
Extended Spectrum $\beta$-Lactamases (ESBL) exhibit most important resistant mechanism challenging broad spectrum of antibiotics, ESBL's hamper current treatment strategies limiting therapeutic options. Hence, it is important to screen those organisms using standard techniques to fix the spread and outcome consequences. Aim and objective of our perspective cohort study was to isolate and to identify the resistant ESBL pathogens from urine samples collected from Urinary Tract Infection (UTI) patients. Among 195 gram negative isolates, 10 consecutive ESBL positive strains were recovered by Disc Diffusion Test (DDT) and $90 \%$ of the isolates were E. coli and Klebsiella pneumoniae. Further, antibiotic susceptibility assay against third line cephalosporins like cefotaxime $(30 \mathrm{~g})$, cefotaxime/clavulanic acid $(30 \mu \mathrm{g} / 10 \mu \mathrm{g})$, ceftazidime $(30 \mu \mathrm{g})$, ceftazidime/clavulanic acid $(30 \mu \mathrm{g} / 10 \mu \mathrm{g})$, ampicillin $(30 \mu \mathrm{g})$ and amikacin $(30 \mu \mathrm{g})$ were tested by CLSI guidelines from NCCLS (National Committee for Clinical Laboratory Standards). Minimum Inhibitory Concentration (MIC) was determined against E-test ESBL strips containing cefotaxime (CT), cefotoxime/clavulanate (CTL), ceftazidime (TZ), ceftazidime/Clavulanate (TZL). E. coli (ATCC 25922) was used as negative control andKlebsiella pneumoniae(ATCC 700603) as a positive control strain. Controls were satisfactory in comparison to standard chart. Our study results unveil a very high spread of such super bugs in health centers. The empiric use of $3^{\text {rd }}$ generation cephalosporins should be curtailed, as it is associated with increased risk of ESBL production. The necessity for continued antimicrobial resistance surveillance to prevent higher degree of resistance is justified in the light of our findings.
\end{abstract}

Keywords: ESBL; $\beta$-Lactamases; Ceftazidime; Antimicrobial resistance; Coliform bacteria; CLSI guidelines

\section{Introduction}

Extended spectrum $\beta$-Lactamases (ESBL) are enzymes produced by pathogens belonging to Enterobacteriaceae, most commonly Escherichia coli and Klebsiella pneumoniae [1]. They cause serious infections and have high mortality rates. Multidrug-resistant ESBL $E$. coli (CTX-M enzyme type) has emerged as an important cause of UTI [2]. ESBL strains are capable of efficiently hydrolyzing many beta-lactam antibiotics including $3^{\text {rd }}$ generation cephalosporins and monobactams. $\beta$-lactamase inhibitors (clavulanic acid, sulbactam, and tazobactam) generally inhibit ESBL producing strains [3]. It is increasingly being reported that they are acquiring a transmissible form of antibiotic resistance. This indicate that penicillins and cephalosporins which have been used for many years are no more effective against ESBL positive [4]. $\beta$-lactamase enzymes undergo changes at nucleotide and amino acid sequences, accordingly, four classes A, C and D (serine based mechanism) and class B (metallo $\beta$-lactamase) are recognized. This can be correlated to ESBL genes CTX-M, TEM, SHV, OXA and AMP-C types [5]. ESBL producing pathogenic enterobacteria poses a serious antibiotic management problem, as these genes are easily transferred from one organism to the other via plasmids [6]. ESBL-containing organisms, which were hitherto found mainly in hospitals, are now becoming fairly common as community acquired infections, especially those of the urinary tract [7]. Findings from a south Indian study documents high prevalence of multidrug resistant CTX-M type ESBL among nosocomial isolates [8]. A report from north Indian tertiary referral hospital documents the presence of blaNDM-1 gene from clinical isolates of Acinetobacter baumannii [9]. Their importance of causing nosocomial and community acquired infections draws our attention even more. ESBL producers do cause UTI, respiratory tract infections, endocarditis etc. resulting in increased treatment cost, morbidity and mortality. In public health, recently, fecal carriage, intestinal colonization, international travel, and household member transmission were also determined to be contributing factors to the spread of ESBL-producing organisms [10-13]. A study from Coimbatore, Tamil Nadu, showed the presence of ESBLs to be $40 \%$ and from Nagpur $50 \%$ in urinary isolates $[14,15]$. In another comparative study it was reported that $68.78 \%$ of gram negative bacteria was found to be ESBL producers [16]. Carbapenems are considered mainstay antibiotics to treat drug-resistant infections [17]. New antibiotics or new combinations of antibiotics would be required to overcome the current threat posed by ESBL pathogens [18]. At present the spread of multidrug-resistant Gram-negative bacteria in the community is a serious problem which needs to be curtailed. In this study, an attempt was made to screen for the presence of ESBL pathogens and confirm their resistant characteristics by phenotypic detection method.

\section{Materials and Methods}

\section{Sample collection}

Urine samples were collected from human volunteers having urinary tract infections visiting Health Center, VIT University, Vellore, Tamil Nadu, India. Samples were collected in a appropriately labeled sterile disposable containers following stringent precautions.

*Corresponding author: Dr. K. Kannabiran, Biomolecules and Genetics Division, School of Biosciences and Technology, VIT University, Vellore-632014, India, Tel: +91 4162202200; Fax: +91 4162243092; E-mail: kkb@vit.ac.in

Received February 18, 2013; Accepted April 17, 2013; Published April 21, 2013

Citation: Subashini J, Kannabiran K (2013) Screening and Identification of Extended Spectrum $\beta$-lactamase (ESBL) Pathogens in Urine Sample of UTI Patient's. Trop Med Surg 1: 120. doi:10.4172/2329-9088.1000120

Copyright: (c) 2013 Subashini J, et al. This is an open-access article distributed under the terms of the Creative Commons Attribution License, which permits unrestricted use, distribution, and reproduction in any medium, provided the original author and source are credited. 
Citation: Subashini J, Kannabiran K (2013) Screening and Identification of Extended Spectrum $\beta$-lactamase (ESBL) Pathogens in Urine Sample of UTI Patient's. Trop Med Surg 1: 120. doi:10.4172/2329-9088.1000120

Page 2 of 4

Volunteers were instructed for clean catch mid-stream urine before collection [19]. Pus samples were collected using sterile swabs from human volunteers with genitourinary problems. The collected swabs were transferred in to nutrient broth within 45 minutes and brought to the laboratory.

\section{Isolation and identification of bacterial isolates}

The transported nutrient broth was incubated at $37^{\circ} \mathrm{C}$ for 24 hours. After incubation, one loopful of culture was inoculated into macconkey agar plates for further studies. Simultaneously, $0.01 \mu \mathrm{l}$ of each urine sample was directly streaked on nutrient broth and incubated at $37^{\circ} \mathrm{C}$ for 24 hours. Morphologically distinct colonies were selectively sub-cultured on mac-conkey agar and incubated at $37^{\circ} \mathrm{C}$ for 24 hours to obtain isolated colonies. After incubation period the plates were observed and identified for the bacterial strains. Gram negative bacteria were taken for biochemical test including mannitol motility, triple sugar ion, indole, citrate, MR, VP and carbohydrate utilization tests for identification [20].

\section{Antibiotic susceptibility test}

Phenotypic confirmation was done by double disc diffusion test (Kirby-bauer) and interpretations were recorded following Clinical Laboratory Standard Institute (CLSI -2010) guidelines [21]. Pure culture of identified bacteria was made to $0.5 \mathrm{McF}$ arland turbidity standards in $0.85 \%$ saline and lawn culture was spread using sterile swabs on Muller Hinton Agar media (Hi-media). Following antibiotics were used, ampicillin $(30 \mu \mathrm{g})$, amikacin, piperacillin-tazobactum, cefotaxime $(30 \mu \mathrm{g})$, cefotaxime/clavulanic acid $(30 \mu \mathrm{g} / 10 \mu \mathrm{g})$, ceftazidime $(30$ $\mu \mathrm{g})$, ceftazidime/clavulanic acid $(30 \mu \mathrm{g} / 10 \mu \mathrm{g})(\mathrm{Hi}$ Media). The plates were then incubated aerobically at $37^{\circ} \mathrm{C}$ for 16 to 18 hours. Klebsiella pneumonia ATCC 700603 (positive control) and Escherichia coli strain ATCC 25922 (negative control) was used for quality control [22].

\section{Detection of ESBL isolates}

Confirmation of ESBL producing strains was made through E-test ESBL strips (AB Biodisk) impregnated with cefotaxime (CT), cefotaxime/clavulanate (CTL) and ceftazidime (TZ), ceftazidime/ clavulanate (TZL) according to manufacturer's instructions. The presence of ESBL was confirmed by the appearance of a phantom zone or deformation of the CT or TZ ellipse or either CT or TZ. MIC is reduced by $\geq 3 \log 2$ dilutions in the presence of clavulanic acid [23].

\section{Results}

Colonies suspected to be coliform based on their gram reaction and cultural morphology (macConkey agar) correlation was identified by cultural and biochemical tests. Culturing of urine sample resulted in isolation of 195 coliform bacteria. All coliform bacteria $(n=195)$ belonging to family Enterobacteriaceae were screened for $\beta$-lactamase production. ESBL positives $(n=10)$ were confirmed from collected urine samples by Disc Diffusion Test (DDT). Other gram negative profile includes E. coli $(\mathrm{n}=44), K$. pneumoniae $(\mathrm{n}=113)$, Citrobacter $\mathrm{sp}$ $(n=2)$, other gram negatives $(n=36)$. Gram negative isolates showed positive for ESBL production is shown in Table 1. Out of $44 \mathrm{E}$. coli isolates 2 were found to be positive for ESBL production, out of $113 \mathrm{~K}$. pneumoniae isolates 7 were positive for ESBL production and out of 2 Citrobacter sp. one isolate was found to be positive for ESBL production. The growth of K. pneumoniae ATCC 700603 (positive control) and the test isolate (ESBL positive) on MacConkey agar is shown in figure 1A respectively. Large encapsulated colony morphology of $K$. pneumoniae on MacConkey agar media was observed. Primary screening by Kirby-

\begin{tabular}{|l|c|c|}
\hline $\begin{array}{l}\text { Total gram negatives } \\
(\mathbf{n}=\mathbf{1 9 5})\end{array}$ & $\begin{array}{c}\text { ESBL Positive } \\
\text { Disc diffusion test } \\
(\mathbf{n}=\mathbf{1 0})\end{array}$ & $\begin{array}{c}\text { ESBL confirmation } \\
\text { E-strips test }(\mathbf{n = 1 0})\end{array}$ \\
\hline E. coli $(\mathrm{n}=44)$ & 2 & 2 \\
\hline Klebsiella pneumoniae $(\mathrm{n}=113)$ & 7 & 7 \\
\hline Citrobacter species $(\mathrm{n}=2)$ & 1 & 1 \\
\hline Others $(\mathrm{n}=36)$ & - & - \\
\hline
\end{tabular}

Table 1: Screening of gram negative isolates for ESBL pathogens.

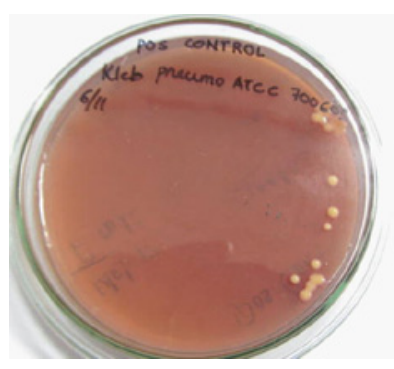

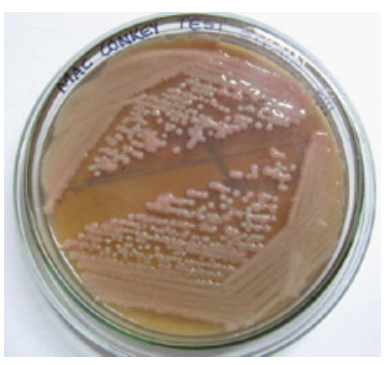

Figure 1: Growth of Klebsiella (positive control) and test strain (ESBL positive) on MacConkey agar.

1A. Large encapsulated colony morphology of Klebsiella pneumoniae on Mac-conkey agar media 1B. Sub-culture of Klebsiella pneumoniae culture.

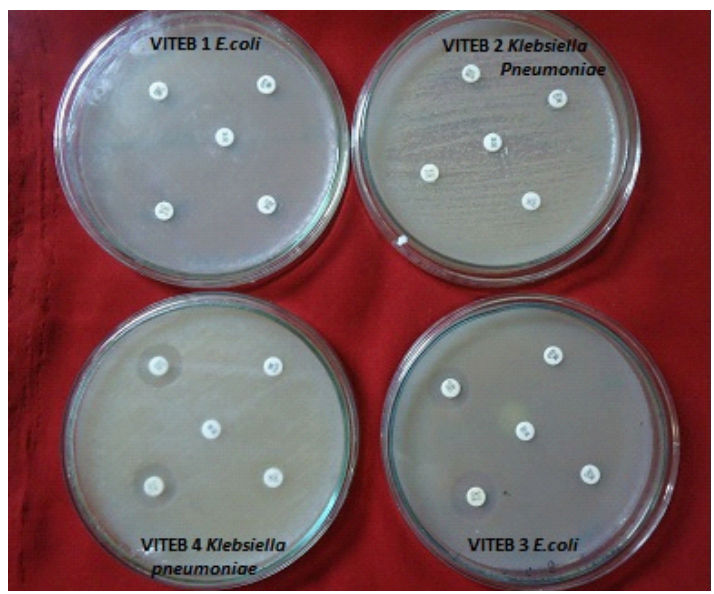

Figure 2: Disc diffusion test showing positive ESBL results.

bauer method for ESBL strains were further confirmed with disc diffusion test. The positive ESBL isolates showed the inhibition zone by disc diffusion is shown in figure 2. ESBL production by positive isolates was further confirmed by E-test ESBL strips and is shown in figure 3 . E-test ESBL strips and antibiotic sensitivity profile for positive ESBL isolates using disc diffusion test and E-test are given in table 2. All the ESBL producing isolates showed varying sensitivity towards different third generation antibiotics tested. The present study highlights the importance of routine screening and alsoexplicitly reports the presence of ESBL producers, Multi Drug Resistance (MDR) isolates in small health center setups.

\section{Discussion}

Clinical and Laboratory Standards Institute (CLSI) and the UK Health Protection Agency (HPA) have published guidelines for ESBL detection in Enterobacteriaceae specifically for E. coli, Klebsiella species, 


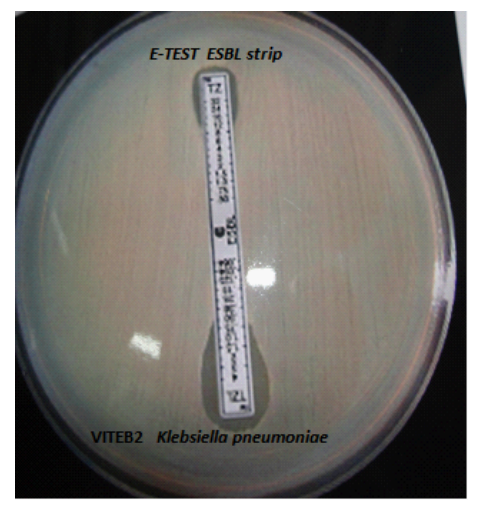

Figure 3: Disc diffusion test showing positive ESBL results.

\begin{tabular}{|l|l|l|l|l|l|l|l|l|l|l|l|}
\hline Strains & \multicolumn{9}{|c|}{ Disc Diffusion } & \multicolumn{4}{c|}{ E-Test } & Organism \\
\cline { 2 - 10 } & CTX & $\begin{array}{l}\text { CTXI } \\
\text { CLAV }\end{array}$ & CZD & AMP & $\begin{array}{l}\text { CZD/ } \\
\text { CLAV }\end{array}$ & CT & CTL & TZ & TZL & \\
\hline VITEB1 & 0 & 16 & 8 & 6 & 15 & $>16$ & 0.094 & $>32$ & 0.75 & E.coli \\
\hline VITEB2 & 6 & 15 & 6 & 6 & 15 & $>16$ & 0.125 & $>32$ & 0.25 & K.pneumoniae \\
\hline VITEB3 & 12 & 23 & 10 & 6 & 21 & $>16$ & 0.125 & $>8$ & 0.19 & E.coli \\
\hline VITEB4 & 10 & 20 & 8 & 6 & 20 & $>16$ & 0.125 & $>32$ & 0.25 & K.pneumoniae \\
\hline VITEB5 & 6 & 6 & 6 & 6 & 6 & $>16$ & 0.125 & $>32$ & 0.5 & K.pneumoniae \\
\hline VITEB6 & 6 & 15 & 6 & 6 & 14 & $>16$ & 0.047 & $>32$ & 0.38 & K.pneumoniae \\
\hline VITEB7 & 6 & 6 & 6 & 6 & 6 & $>16$ & 0.047 & $>32$ & 0.38 & K.pneumoniae \\
\hline VITEB8 & 6 & 6 & 6 & 6 & 6 & $>16$ & 0.094 & $>32$ & 0.38 & K.pneumoniae \\
\hline VITEB9 & 15 & 22 & 6 & 6 & 15 & $>16$ & 0.125 & $>32$ & 0.25 & Citrobacter diversus \\
\hline VITEB10 & 6 & 15 & 6 & 6 & 14 & $>16$ & 0.125 & $>32$ & 0.38 & K.pneumoniae \\
\hline
\end{tabular}

Discs

CTX-Cefotaxime $30 \mu \mathrm{g}$

CTX/CLAV-Cefotaxime/Clavulanic acid 30/10 $\mu \mathrm{g}$

CZD-Ceftazidime $30 \mu \mathrm{g}$

CZD/CLAV-Ceftazidime/Clavulanic acid 30/10 $\mu \mathrm{g}$

AMP-Ampicillin $30 \mu \mathrm{g}$

E-Strips

CT-Cefotaxime $30 \mu \mathrm{g}$

CTL-Cefotaxime $30 \mu \mathrm{g} /$ Clavulanic acid

TZ-Ceftazidime $30 \mu \mathrm{g}$

TZL-Ceftazidime/Clavulanic acid 30/10 $\mu \mathrm{g}$

Table 2: Antibiotic sensitivity assay of ESBL pathogens isolated from urine samples.

and Proteus sp [24,25]. As per these guidelines the ESBL producing organism should be resistant to all cephalosporins except cephamycins and monobactams. $\beta$-lactam/ $\beta$-lactamase inhibitor combinations such as piperacillin/tazobactam and cefaperazone/sulbactam may be reported as sensitive. Non-ESBL-producing organism E. coli ATCC 25922 and a positive ESBL organism Klebsiella pneumoniae ATCC 700603 may be used as controls to perform the tests. ESBL's are mostly detected by disc approximation and double disc synergy methods. For the double-disc synergy test, the antibiotic impregnated discs were placed $30 \mathrm{~mm}$ away from each other. ESBL production was considered positive when an enhanced zone of inhibition of $\beta$-lactamase inhibitorcontaining disc, ceftazidime/clavulanic acid $(30 \mu \mathrm{g} / 10 \mu \mathrm{g})$ was $\geq 5$ $\mathrm{mm}$ than the antibiotic containing ceftazidime $(30 \mu \mathrm{g})$ alone $[26,27]$. However, phenotypic confirmation test should be carried out to ascertain the diagnosis.

Urinary tract infection is one of the commonest bacterial infections in adults. Current update on antimicrobial resistant pathogens is mandatory [28]. The production of beta-lactamase may be of chromosomal or plasmid origin. Plasmid mediated production is often acquired by transfer of genetic information from one organism to another. Such transferable plasmid also codes for resistant determinants to other antimicrobial agents. Hence multidrug resistance is expected to be more common in ESBL producing organisms [29]. In this study ESBL producing urinary pathogens were found to be resistant to third generation cephalosporins, evidencing the worsened situation in health centers due to increased spread of multidrug resistance. An updated standard technique for routine screening of ESBL uropathogens along with conventional antibiogram useful to all health centers is recommended. Carbapenems are the mainstay of therapy but, they are expensive and require prolonged intravenous administration. The circumstances have changed and growing carbapenem resistance is a major clinical concern [30]. Fosfomycin, and tigecycline, colistin and gentamycin have shown to be effective in most cases [31]. The degree of resistance is highly variable among ESBL enzymes [32]. Improved techniques like PCR and DNA sequencing need to be used for detection and typing of different ESBL enzymes. Considering the complicated task of ESBL identification due to their competing resistance over broad spectrum $\beta$-lactam antibiotics and increased spread via plasmid mediated transfer there is an urgent need for standard routine screening and detection in all the health centers.

\section{Conclusion}

In our cohort study an ESBL producing Citrobacter species resistant to $3^{\text {rd }}$-line cephalosporin's, ceftazidime $(30 \mu \mathrm{g})$, ceftazidime/ clavulonic acid $(30 \mu \mathrm{g} / 10 \mu \mathrm{g})$ were isolated and identified. The results of our study further confirmed that ESBL producing pathogens were more prevalent in urinary tract infections. Degree of resistance is highly variable among ESBL enzymes, hence molecular methods like PCR and DNA sequencing need to be used for detection and typing of different ESBL enzymes.

\section{Acknowledgement}

The authors thank the management of VIT University for providing facilities to carry out this work.

\section{References}

1. Kenneth S, Thomson (2010) Extended-spectrum- $\beta$-lactamase, AmpC, and Carbapenemase J.Clin Microbiol 48: 1019-102.

2. Gisele P. David R, Jana N, Allison M, Vivian L, Baldwin T, et al. (2010) High Prevalence of ST131 Isolates Producing CTX-M-15 and CTX-M-14 among extended-spectrum- $\beta$-lactamase-producing Escherichia coli isolates from Canada.Antimicrob Agents Chemother 54: 1327-1330

3. Rupp ME, Fey PD (2003) Extended- spectrum $\beta$-lactamase(ESBL)-producing Enterobacteriaceae: considerations for diagnosis, prevention and drug treatment. Drugs 63: 353-365.

4. Ben-Ami R, Rodríguez-Baño J, Arslan H, Pitout JD, Quentin C, et al. (2009) A multinational survey of risk factors for infection with extended-spectrum betalactamase-producing enterobacteriaceae in nonhospitalized patients. Clin Infect Dis 49: 682-690.

5. Karen B, George A, Jacoby (2009) Updated functional classification of $\beta$-lactamases. Antimicrob. Agents Chemother 54: 3969-3997.

6. Vaidya VK (2011) Horizontal Transfer of Antimicrobial Resistance by ExtendedSpectrum $\hat{I}^{2}$-Lactamase-Producing Enterobacteriaceae. J Lab Physicians 3 : 37-42.

7. Khanfar HS, Bindayna KM, Senok AC, Botta GA (2009) Extended spectrum beta-lactamases (ESBL) in Escherichia coli and Klebsiella pneumoniae: trends in the hospital and community settings. J Infect Dev Ctries 3: 295-299.

8. Baby Padmini S, Appala Raju B, Mani KR (2008) Detection of Enterobacteriaceae producing CTX-M extended spectrum beta-lactamases from a tertiary care hospital in south India. Indian J Med Microbiol 26: 163-166.

9. Mishra S, Sen MR, Upadhyay S, Bhattacharjee A (2013) Genetic linkage of blaNDM among nosocomial isolates of Acinetobacter baumannii from a tertiary referral hospital in northern India. Int J Antimicrob Agents 41: 452-456. 
Citation: Subashini J, Kannabiran K (2013) Screening and Identification of Extended Spectrum $\beta$-lactamase (ESBL) Pathogens in Urine Sample of UTI Patient's. Trop Med Surg 1: 120. doi:10.4172/2329-9088.1000120

10. Laupland KB, Church DL, Vidakovich J, Mucenski M, Pitout JD (2008) Community-onset extended-spectrum beta-lactamase (ESBL) producing Escherichia coli: importance of international travel. J Infect 57: 441-448.

11. Rodríguez-Baño J, López-Cerero L, Navarro MD, Díaz de Alba P, Pascual A (2008) Faecal carriage of extended-spectrum beta-lactamase-producing Escherichia coli: prevalence, risk factors and molecular epidemiology. J Antimicrob Chemother 62: 1142-1149.

12. Valverde A, Grill F, Coque TM, Pintado V, Baquero F, et al. (2008) High rate of intestinal colonization with extended-spectrum-beta-lactamase-producing organisms in household contacts of infected community patients. J Clin Microbiol 46: 2796-2799.

13. Ho PL, Wong RC, Chow KH, Yip K, Wong SS, et al. (2008) CTX-M type betalactamases among fecal Escherichia coli and Klebsiella pneumoniae isolates in non-hospitalized children and adults. J Microbiol Immunol Infect 41: 428-432.

14. Babypadmini S, Appalaraju B (2004) Extended spectrum-lactamases in urinary isolates of Escherichia coli and Klebsiella pneumoniae-prevalence and susceptibility pattern in a tertiary care hospital. Indian J Med Microbiol 22: 172 174

15. Tankhiwale SS, Jalgaonkar SV, Ahamad S, Hassani U (2004) Evaluation of extended spectrum beta lactamase in urinary isolates. Indian J Med Res 120: 553-556.

16. Mohanty S, Singhal R, Sood S, Dhawan B, Das BK, et al. (2005) Comparative in vitro activity of beta-lactam/beta-lactamase inhibitor combinations against gram negative bacteria. Indian J Med Res 122: 425-428.

17. Rupp ME, Fey PD (2003) Extended spectrum beta-lactamase (ESBL)producing Enterobacteriaceae: considerations for diagnosis, prevention and drug treatment. Drugs 63: 353-365.

18. Jonathan N (2005) Screening for extended-spectrum beta-lactamaseproducing pathogenic enterobacteria in district general hospitals. J Clin Microbiol 43: 1488-1490.

19. Harwalkar A, Sataraddi J, Gupta S, Yoganand R, Rao A, et al. (2013) The detection of ESBL-producing Escherichia coli in patients with symptomatic urinary tract infections using different diffusion methods in a rural setting. $J$ Infect Public Health 6: 108-114.

20. Birgul K (2010) Investigation of extended spectrum beta lactamase production of bacteria by direct urine inoculation. African J Microbiol Res 4: 1087-1090.
21. Manoharan A, Premalatha K, Chatteriee S, Mathai D; SARI Study Group (2011) Correlation of TEM, SHV and CTX-M extended-spectrum beta lactamases among Enterobacteriaceae with their in vitro antimicrobial susceptibility. Indian J Med Microbiol 29: 161-164.

22. Jorgensen JH, Ferraro MJ (2009) Antimicrobial susceptibility testing: a review of general principles and contemporary practices. Clin Infect Dis 49: 1749-1755.

23. Lalitha MK, Manual on antimicrobial susceptibility testing. Performance standards for antimicrobial testing: Twelfth Informational Supplement 56238 : $454-6$.

24. Wayne, PA (2002) National committee for clinical laboratory standards, performance standards for antimicrobial susceptibility testing. $12^{\text {th }}$ informational Supplement. M 100-S12.

25. Health Protection Agency (2012) Laboratory detection and reporting of bacteria with extended spectrum $\beta$-lactamases. UK Standards for Microbiology Investigations 3: 2

26. Cheesbrough M (1989) Medical laboratory manual for tropical countries: Microbiology, Butterworth-Heinemann, Cambridge, Great Britain, 10: 462.

27. Schwaber MJ, Raney PM, Rasheed JK, Biddle JW, Williams P, et al. (2004) Utility of NCCLS guidelines for identifying extended-spectrum beta-lactamases in non-Escherichia coli and Non-Klebsiella spp. of Enterobacteriaceae. J Clin Microbiol 42: 294-298.

28. Patankar M, Sukumaran S, Chhibba A, Nayak U, Sequeira L (2012) Comparative in-vitro activity of cefoperazone-tazobactam and cefoperazonesulbactam combinations against ESBL pathogens in respiratory and urinary infections. J Assoc Physicians India 60: 22-24.

29. Livermore DM, Brown DFJ (2001) Detection of $\beta$-lactamase-mediated resistance. J Antimicrobial Chemotherapy 48: 59-64.

30. Mohamudha Parveen R, Manivannan S, Harish BN, Parija SC (2012) Study of CTX-M Type of Extended Spectrum $\hat{I}^{2}$-Lactamase among Nosocomial Isolates of Escherichia coli and Klebsiella pneumoniae in South India. Indian J Microbio 52: $35-40$

31. Stéphane C, Ulrika F, Bertrand B, Olivier B, Andrej T (2013) Activity of fosfomycin, tigecycline, colistin and gentamicin against extended spectrum beta-lactamase (ESBL)-producing $E$. coli in a foreign-body infection model. Antimicrobial Agents Chemotherapy 57: 1718-12.

32. Taneja N, Sharma M (2008) ESBLs detection in clinical microbiology: why \& how? Indian J Med Res 127: 297-300. 